\title{
The Conditional Sink: Counterfactual Display in the Valuation of a Carbon Offsetting Reforestation Project
}

\author{
Véra Ehrenstein and Fabian Muniesa
}

\begin{abstract}
This paper examines counterfactual display in the valuation of carbon offsetting projects. Considered a legitimate way to encourage climate change mitigation, such projects rely on the establishment of procedures for the prospective assessment of their capacity to become carbon sinks. This requires imagining possible worlds and assessing their plausibility. The world inhabited by the project is articulated through conditional formulation and subjected to what we call "counterfactual display": the production and circulation of documents that demonstrate and configure the counterfactual valuation. We present a case study on one carbon offsetting reforestation project in the Democratic Republic of Congo. We analyse the construction of the scene that allows the "What would have happened" question to make sense and become actionable. We highlight the operations of calculative framing that this requires, the reality constraints it relies upon, and the entrepreneurial conduct it stimulates.
\end{abstract}

Key words: carbon offsetting; reforestation; Democratic Republic of Congo; valuation; counterfactuals

Carbon offsetting constitutes one of the most widely used schemes for mitigating carbon release into the atmosphere. Reforestation projects can benefit financially from future carbon credits purchased by

Véra Ehrenstein, Centre de Sociologie de l'Innovation, Mines ParisTech, France, vera.ehrenstein@mines-paristech.fr

Fabian Muniesa, Centre de Sociologie de l'Innovation, Mines ParisTech, France, fabian.muniesa@mines-paristech.fr

Editor's note: One of the authors of this article, Fabian Muniesa, is a co-editor of Valuation Studies. Therefore, co-editor Claes-Fredrik Helgesson has handled the editorial and review process of this contribution.

(C) 2013 Véra Ehrenstein and Fabian Muniesa

LiU Electronic Press, DOI 10.3384/vs.2001-5992.1312161

http://valuationstudies.liu.se 


\section{Valuation Studies}

emitters (e.g. industrial companies) on the basis of the envisaged capacity of tree plantations to store carbon. But the actualization of this capacity and the value of an offsetting reforestation projectexpressed in terms of purchasable emissions reductions-remains uncertain until the trees have grown enough so their carbon stock can be effectively quantified. Offsetting projects thus provide an opportunity to refine our understanding of projective valuation processes. In particular, they let us examine the meanders of what we call "counterfactual display": how two future states of the world-one with the project and one without it - are played against each other and how the value of the project is derived from that interplay. We use the term "display" to emphasise the material-semiotic arrangement of counterfactual operations. These do not rely solely on reasoning and imagination, but also require the production, circulation, and exhibition of documents and devices essential to valuation processes.

Our contribution draws from a qualitative case study; we offer an empirical account of the procedures and conditions of counterfactual display in one particular project. While our analytical claims keep to the case, they aim at serving the lineaments of a sociological approach to counterfactual display in valuation studies. The case study focuses on a reforestation project in the Democratic Republic of Congo. The project is led by an entrepreneur who we call Olivier, a BelgianCongolese agricultural engineer who runs a small family-owned business. Olivier plans to reforest 4200 hectares of savannah in a customary-owned area situated 150 kilometres north of Kinshasa, the capital of the country. In February 2011, the project was registered as part of the carbon market scheme created to reduce greenhouse gas emissions, under the supervision of the United Nations. The registration confirms the relevance of Olivier's project for climate change mitigation; the plantation is expected to store more than 1.5 million tons of carbon dioxide $\left(\mathrm{CO}_{2}\right)$ between 2008 , the starting date of the project, and 2037. In 2011, the sequestration potential had been estimated, but its realization is not yet ensured. The relevance of the project is conditional. Its value is an expected value. However, Olivier has already sold some of the carbon credits that might be issued in the future to buyers interested in emissions offsetting.

Expectations about future states of the world can be the object of economic agreements in the present. These kinds of processes entail developing practices of projection and estimation, which have been studied at length in social-scientific literature. Economic sociology counts on significant discussions of the role that fictional expectations play in the organization of capitalist economies (e.g. Beckert 2013a, $2013 \mathrm{~b}$ ). Research on the development of new derivative markets has stressed the problems with the conventions of valuation that need to be put in place (Huault and Rainelli-Weiss 2011). Studies in the performative capacities of business plans and business models have 
also contributed extensively to the understanding of the processes through which future scenarios of entrepreneurial ventures and their value are constructed (Giraudeau 2008; Doganova and EyquemRenault 2009). Anthropologists have explored at length the articulation of hope, future and prospect in economic endeavours (Maurer 2002; Elyachar 2005; Miyazaki 2006; Guyer 2007). Historical approaches to the politics of science and technology have highlighted the rationales of simulation techniques and forecasting methods in the construction of both economic and political realities (Armatte 2008; Dahan 2010; Edwards 2010; Jasanoff and Kim 2009; Mallard and Lakoff 2011). These analyses share what we could call a performative understanding of prospective valuation techniques: they consider that devices representing future states are tools through which the world is indeed transformed. Such work informs our viewpoint. Our contribution highlights the problems with counterfactual display, how it works, and what it means.

Three salient points characterise our contribution. The first is that counterfactual display requires a contrived scene, a calculative space or "centre of calculation" (Latour 1987) that has been carefully prepared to host prospective valuation. The second is that the rules governing counterfactual display rely on a realist approach (Stalnaker 1984) in which the "possible worlds" manipulated within the display characterise the present world. The third point is that counterfactual display emphasises an entrepreneurial interpretation of political (environmental) action and, accordingly, a certain spirit of capitalization, quite resonant with a neoliberal "project polity" (Boltanski and Chiapello 2005).

In the first section we present our research methodology. In the next section, we describe the tactical, political work necessary to frame the project as an object of prospective calculation. We outline the scheme and regulation in which our case study develops, climate change negotiations, the Kyoto Protocol, and its Clean Development Mechanism (CDM). We also introduce the main vehicle through which the prospective valuation of the offsetting project is performed and can thus be analysed, the Project Design Document (PDD). In the third section, we analyse the counterfactual display proper. We describe three prospective operations: first the delimitation of the project's perimeter and characteristics, then the establishment of a reference scenario against which to value the project scenario, and finally the estimation of the expected carbon credits. In the final section, we highlight our research results by discussing calculative contrivance, counterfactual reality, and entrepreneurial drive. In our conclusion, we suggest a few directions for consideration. 


\section{Valuation Studies}

\section{Methodology}

Our case study relies on data gathered by the first co-author through field observations and interviews in Paris from January to March 2010 and in the Democratic Republic of Congo in March and April 2011. Semi-structured interviews were carried out with the project developer, consultants involved in preparing the project's registration, representatives of the organizations acting as credit buyers or investors for the project, and members of the Congolese administration. A total of nine interviews were carried out with eight actors and the interviews were recorded and transcribed. Field notes were produced regularly during the ethnographic missions. Access was granted to day-to-day project-related work during fieldwork in the Congo and also to all relevant project-related documentation. This documentation was reviewed in depth. ${ }^{1}$

Our qualitative analysis proceeded principally in a descriptive manner. We examined the textual accounts of the project, in particular the PDD, which describes the project for the purpose of registration, and the numerous documents it relies on (the modalities of the scheme, standard methods of demonstration, decisions by the regulator, etc.). We analysed the operations done in and by this documentation, in the light of field interviews and observations. This focus on paper devices was a deliberate choice because the scheme places considerable importance on documentation. The description and projection of the future activity is thus a key component in the analysed carbon market. Our approach was grounded in the material-semiotic stance of actornetwork theory, which directs attention to operations of translation and the trails through which they are enacted (e.g. Callon 1986; Callon and Latour 1981; Latour 1983). The theoretical conclusions that we draw, in other words, our characterisation of counterfactual display, were extracted from the elements we observed.

\section{The Carbon Market and Its Framing}

\section{Registering a Forestry Carbon Offsetting Project}

Perceived as a cost-effective approach to reduce greenhouse gas emissions, carbon offsetting was implemented as a global policy response to climate change through the CDM, which is a project-based carbon market. The CDM is one of the policy instruments contained in the Kyoto Protocol that was established in the late 1990s (UNFCCC 1997). The CDM is a means to involve so-called developing countries in climate change mitigation. Developed countries are the only countries committed to emissions reduction, according to the Kyoto

\footnotetext{
${ }^{1}$ The case study benefitted from the insights gained from a wider research project on international adjustments, tropical forests and carbon arrangements, carried out by the first co-author in the context of a doctoral project.
} 
Protocol. Their governments and private companies can use the CDM to compensate for their emissions by contributing to mitigation activities in the developing world. An offsetting project is expected to lower $\mathrm{CO}_{2}$ emissions and generate Certified Emission Reductions (CERs) (i.e. carbon credits). Reforestation is one of the eligible activities. In short, trees can be considered carbon sinks, planting them can be considered a way to remove carbon from the atmosphere, doing so can be considered a way to reduce emissions compared to what would have happened without such an initiative, and this can be considered a valuable service. The CDM has thus created a new economic activity: producing carbon credits and selling them to polluters wanting to compensate for their emissions.

This market differs from a cap-and-trade system where permits are allocated to polluters who can then trade them. In the CDM, carbon credits are literally produced, not assigned; they are created from projects in developing countries (MacKenzie 2009a, 137-176). By using the word "project" we mean a planned activity that will translate into a small-scale activity implemented by a few individuals during a given period of time. The market fosters the implementation of projects that would not have otherwise been developed and whose outcome-or one of their outcomes-is a new product: emissions reductions exchangeable in the form of carbon credits. Whereas capand-trade carbon markets heavily rely on models developed by economists, the project-based carbon markets have developed in a more experimental and practical manner (Callon 2009).

The CDM is organized as a certification scheme. Its ultimate authority is the Conference of the Parties of the United Nations Framework Convention on Climate Change (UNFCCC), which is composed by representatives of all the states recognizing the Convention-namely almost all countries in the world. Day-to-day supervisory work is undertaken by the Executive Board, a regulatory body that establishes the rules of the mechanism (UNFCCC 2001). The Executive Board decides whether projects presented by project developers such as Olivier will be formally accepted as activities capable of generating carbon credits. The process, through which carbon credits are issued, the CDM cycle, is marked by formal steps. To become part of this market, a project must be submitted to the Board and evaluated by an independent auditor. Once validated and registered, the activity is implemented and monitored by the project developer. Claims for the reduction of emissions must then be periodically verified by auditors in order for carbon credits to be issued. At the early submission stage, the value of the activity is estimated according to its potential contribution to a desirable effectemissions reduction. This crucial step is carried out through the production and evaluation of the Project Design Document (PDD), a mandatory form that plays an essential role, from the very conception 


\section{Valuation Studies}

of the project to the issuance of carbon credits some years after registration.

Different kinds of activities-from reforestation to waste disposal and hydropower dams-can be developed within the CDM. A variety of economic calculative instruments (MacKenzie 2009b), but also administrative procedures, narrative descriptions, property rights, and commercial contracts translate into the same outcome: emission reductions, in different quantities. The inclusion of forestry activities in this market has sparked controversy in climate change negotiations (Boyd, Corbera, and Estrada 2008; Lövbrand 2009). Offsetting reforestation projects have been criticized because they prompt a shift of responsibility from the industrial sector of developed countries to developing countries where local access to forestry resources may be hampered by such projects (Bäckstrand and Lövbrand 2006; Corbera and Brown 2008; Boyd 2009). While recognizing the relevance of such condemnation, we adopt a different perspective. We, too, are interested in showing the configuration of power relationships, but we suggest investigating them by focusing on the prospective economic operations required by the CDM that produce an uneven distribution of capacities to intervene (Callon and Muniesa 2005).

\section{Writing Down Prospective Operations That Need to be Actualized}

As indicated, a project developer who wants to register a project has to submit an extensive description of the foreseen activity in the PDD. The document must establish timelines, it must present the technologies that will be used and describe the context of implementation. It must also identify the project participants and their characteristics. It has to display stabilized information, because the information will be used as reference during the implementation of the project.

In addition to the description of the project, the PDD contains other crucial narratives: a description of how the "baseline" is determined, a demonstration of the project's "additionality," and an "ex-ante estimation" of greenhouse gas emissions. The baseline represents what will happen in terms of greenhouse gas emissions if the project is not implemented. In other words, it describes a hypothetical situation in which the projected activities do not take place. The developer has to elaborate on this scenario to demonstrate the additionality of the emissions reduction. A project is considered additional if it cannot be implemented without access to the carbon market, that is, without the possibility of selling carbon credits. A CER generated by an activity represents one ton of $\mathrm{CO}_{2}$ (or equivalent) whose release into the atmosphere has been avoided by virtue of the project benefitting from the carbon market. It corresponds to the difference between the baseline greenhouse gas emissions-the amount 
of $\mathrm{CO}_{2}$ that would have been released in the absence of the reforestation activity - and the actual emissions-the amount released by the projected activity (UNFCCC 2005). To obtain an ex-ante estimation of carbon credits, the developer has to quantify the level of emissions in the baseline scenario and the actual scenario and then subtract the latter from the former.

Once the PDD is finalized, it is submitted to a Designated Operational Entity (DOE), an independent private auditor accredited by the Executive Board. The auditor carries out the validation of the project: an evaluation of the project design and its projected benefits, which is based mainly on a short field visit and an extensive analysis of the PDD and its annexes (baseline methodology, calculation sheets, financial estimates, technical feasibility study, social and economic impact assessment, title deed, etc.). Once validated, a project requires further assessment from the Executive Board. If the latter ratify the validation report the project is registered. This happened to Olivier's reforestation project in February 2011.

After the project is registered, the PDD serves as a reference for its implementation and the monitoring of the reductions and their successive verifications by other independent auditors. This process is similar to contemporary audit practices of verification, which routinely rely on a ritualized referential work (Power 1997). Verifications will be run periodically during the crediting period. In Olivier's project that is supposed to be thirty years, from 2008 to 2037. Verification reports are based on the monitoring of data, which will have to be in line with what was documented in the PDD. Written acknowledgements of the fact that the activity has indeed reduced emissions follow. The Executive Board then issues the specified quantity of CERs for the corresponding period on the registry accounts of project participants. CERs are created, held, and transferred on an electronic database supervised by the Executive Board (UNFCCC 2005).

What happens throughout the drafting, submission, and evaluation of the project is crucial not only for the registration of the activity, but also for its subsequent implementation. Indeed, the scheme is organized to guarantee that the project developer respects and implements the project as described in the PDD. This document, and the audit procedures it is subjected to, makes the project governable by the international decision-making process on climate change acting through the Executive Board of the CDM.

\section{Political Work and the Establishment of Calculability}

In order for the PDD to make sense, a set of dramatis personae needs to be established: principally the project developer and the purchasers of credits. The formation of these economic agents and the omission of other actors from the scope of the project and the transaction require political work, which is carried out previous to the presentation of the 


\section{Valuation Studies}

project to the Executive Board for registration. To become the owner and seller of future carbon credits, Olivier's undertakings included the establishment of business networks and engagement with state apparatuses, public administrations, and local communities. A number of inscriptions (letter of intent, property rights, notarial act, and letter of approval) are used in the framing process, which transform the elaboration of the project into a matter of conditional prospective calculation.

In his original project, which was crafted in the late 1990s, Olivier had not intended to engage in climate change mitigation. Reforestation of family-owned land was envisaged with the purpose of producing charcoal. Political turmoil, and then war, jeopardized fundraising. In the early 2000s, when the Democratic Republic of Congo started to move to a less troubled situation, the project was still not considered a viable business by the investors Olivier approached. In the mid-2000s, Olivier identified the emergence of the carbon market as a potential opportunity to transform his unsuccessful project into a commercial activity. The World Bank had just created the BioCarbon Fund, a fund dedicated to the development of forestry projects in the CDM. Olivier submitted his reforestation project to the formal selection process and contacted representatives of the international organization in Kinshasa. These moves led to the signing of a letter of intent, which outlined an agreement between the fund as a credit buyer and Olivier as a project developer. The expression of the World Bank's intent in this quasi-legal document enabled Olivier to persuade investors and raise capital.

To become certified by the CDM, a project requires an authorization from the government of the developing country in which the activity will be implemented. This translates into the receipt of a letter of approval in which the government acknowledges the existence of the project and declares that it will contribute to the sustainable development of the country. According to the rules of the scheme, each country is expected to establish a national authority to issue this approval. To provide the formal authorization of Olivier's project the Ministry of the Environment of the Democratic Republic of Congo had, actually, to create the required national institution. In the letter of approval the Congolese government expressed a loose form of sovereign control over the carbon offsetting project. The document is a minimal vehicle of sovereign power, indeed, since it enacts the government's withdrawal from the project and the economic transaction the activity will be part of. This exemplifies to some extent the transformation of sovereign power that a "politics of economization" induces (see Foucault 2008) and is in line with a number of insights put forward in the literature on "carbon governmentality" (e.g. Lövbrand and Stripple 2012; Lovell and Liverman 2010). 
The transformation of the initial project into a carbon project required Olivier, the project developer, to become the owner of the future emissions reductions. As in other forms of commodification, the establishment of formal property rights, as opposed to so-called "informal" ones, is crucial (Mitchell 2007). The texts setting the modalities of the carbon market do not provide a standard rule for the clarification of carbon property issues. For each project, a singular legal arrangement has to be constructed. In Olivier's case, the arrangement was settled at the initiative of the World Bank, which required the establishment of explicit property rights during the due diligence phase of the project. The lack of written proof of any such rights (this is a case of informal property, indeed) prompted a process of clarification. The project's land was subject to customary ownership rights, which Olivier inherited from his father. But the latter had not rendered his customary owner status into a state-delivered title, and the war that shook the country in the late 1990s and early 2000s favoured erratic evolutions in the occupation of the land. The clarification process involved, on one hand, negotiations with other customary chiefs to determine which area belonged to his family and, on the other hand, the procurement of a legal title. The recognition of Olivier's traditional authority of eight thousand hectares of land was formalized through a notarial act, and then the entrepreneur obtained a title from the state for six thousand hectares of the area.

Both processes were supervised by representatives of the World Bank. The institution was interested in the second process to guarantee the ownership of the credits. It also paid attention to the first one because recognition of Olivier's customary rights by the other chiefs constituted a means to evaluate the support of the surrounding communities for the project. A former representative of the World Bank involved in the BioCarbon Fund indicated that "in case of private property such as this one, it was important to make sure that there had been no despoliation of the poorest local communities" (Interview, January 18, 2010). According to Olivier, the organization "worried" about whether or not he was going to redistribute some of the future (and potential) benefits to the people living near the project area (Interview, March 17, 2010). The PDD indicates that $12 \%$ of the benefits generated by the sale of the credits would be used for so-called social investment. No details are given, however, about the kind of reality this ought to translate into (e.g. educational facility, healthcare centre, or else). The presence of the socalled local communities in the PDD is only rendered through such kinds of percentages, a tendency in development policies that has been amply criticized in the case of the CDM (see Fogel 2004) and more broadly in development projects (see Li 2007).

The PDD represents the project as an arrangement between economic parties in a transaction on carbon credits. The spatial and 


\section{Valuation Studies}

temporal frames are settled, the current state of economic properties and identities is guaranteed. All that needs to be done for the project to make sense is to establish a calculative space to determine the conditions and the likelihood of the project's future value. As noted, this state of affairs is only possible through intense political work that is contained (both in the sense of accommodating and of curbing) within the prospective device.

\section{Counterfactual Display}

\section{The Description of the Project: Delimitation and Capitalization}

The PDD constitutes, first and foremost, an elaborate description of what will happen if the project is implemented, compared to a more short description of what would happen if it is not. As such, the PDD is a scene of a series of rhetorical moves that, together, construct the counterfactual display. Filling in the form, understanding its interpretive intricacies, and clearly demonstrating the project's realism, desirability, and appropriateness, require particular expertise, and that is why Olivier contracted the services of a specialized consultancy firm. As in the case of stream restoration and wetland mitigation banking, a consultancy industry practicing a "private sector science" has developed on climate change and offsetting issues (Lave, Doyle and Robertson 2010).

The description of the project starts with the delineating of the project's boundaries and a precise description of the object under the control of the project developer. The first boundary is temporal: the project developer has to determine the duration of the activity. The document indicates that Olivier's reforestation project will last at least thirty years. Supposing that the CDM still exists by the end of that period (its maintenance depends on the outcome of international negotiations), the project could generate carbon credits until 2037. The second boundary is spatial: the document must state the geographical coordinates of the reforested area. In Olivier's project, this means delimiting the 4200 hectares that will be monitored. The PDD form indicates that the circumscribed land has to be eligible for the CDM. This means showing that the project is "implemented on degraded lands, which are expected to remain degraded or to continue to degrade in the absence of the project, hence the land cannot be expected to revert to a non-degraded state without human intervention" (Field document: PDD, December 1, 2010, p. 32). Olivier's PDD explains that the project activity "will be implemented on savannah grassland that is subject to repeated annual wildfires," adding that "this main factor of degradation greatly reduces existing natural vegetation cover" (Field document: PDD, December 1, 2010, p. 34). In other words, the activity will appreciate the value of a degraded asset. 
Once the geographical boundary has been determined and the eligibility of the land demonstrated, the document assesses potential leakages. Leakages are emissions that the implementation of the project could provoke outside the boundary, for example, by displacing or encouraging harvesting outside the perimeter. Olivier's PDD uses a very low population density (eight inhabitants per $\mathrm{km}^{2}$ ) as an argument against the likelihood of such leakage. The description of how leakage is expected to be minimized is followed by a reference to the legal title. The acquisition of property rights-both state-supplied and customary-is supposed to guarantee that Olivier effectively controls the area for the next thirty years. The PDD has therefore provided the elements of a calculative space (Callon and Muniesa 2005), that is, a material cognitive surface within which univocally defined entities can be manipulated and in which possible courses of action can be simulated, assessed, and acted upon numerically.

A large part of the document is devoted to the presentation of the reforestation plan, which identifies the main economic objective of the project: to produce charcoal. As counterintuitive as this may sound (using trees as carbon sinks to then produce charcoal and release carbon back again into the atmosphere), the use of trees as wood energy is not prohibited in the CDM scheme, given that the harvest for charcoal production will be deducted from the project's carbon accounting. ${ }^{2}$ In addition, the project will produce timber, cultivate cassava, and store enough carbon to generate credits. The articulation of these different objectives contributes to the configuration of the future planting, which will be composed of acacia, pine, eucalyptus, and some local species. The design and dynamics of the future forest are calculated to optimize the economic viability of the project. Olivier summarizes this tricky operation in the following way:

Goal number one is to begin production of wood energy in the shortest time possible. The wood fuel production is also directly related to the purpose of storing $\mathrm{CO}_{2}$, and, here again, the largest quantity possible in the shortest time possible. And to achieve this, we must work with fast-growing species. It is this reason that determined the choice of acacia. [...]. The other secondary species such as exotic pine and eucalyptus are also included to meet the rapid growth and $\mathrm{CO}_{2}$ storage criteria, with another goal this time, which is the production of timber and lumber on longer cycles, that is to say ten years to twenty-five years. The third category is local species that are slow-growing [...] and because of what I just explained we have chosen much lower percentages. (Interview, March 17, 2010, our translation)

2 Moreover, charcoal is usually obtained through an uncontrolled exploitation of already standing trees, which poses a threat to the last forested land in the savannah. The controlled production of charcoal from reforested land is considered as an environmental improvement. 


\section{Valuation Studies}

Acacia, the main tree species that Olivier expects to plant, constitutes a relatively profitable option, in carbon terms. An agronomist from the consultancy firm hired to write the PDD explained that the profitability is associated with the growth rate of the tree and the density of its wood. Given the poor quality of the soil, acacia can be considered a quick species and its wood is relatively dense. That is why, according to the consultant, Olivier "could hardly find better" (Interview, March 15, 2010). Eucalyptus could have been an alternative. However, cash flows derived from eucalyptus will be realized later than those from acacia because charcoal production will begin more quickly than timber production, with the first harvest of acacia being planned for 2013. Moreover, according to the consultant, acacia is "good for nitrogen fixation," a significant quality given that Olivier plans to cultivate cassava between the trees. This agricultural production is supposed to provide "short-term cash flow for project implementation." Planting acacias is a way to manage and enhance the fertility of the soil, which is otherwise "poor, chemically speaking," in order to quickly generate a return on investment (Interview, March 15, 2010).

The choice of species, their exploitation rate, and their distribution on the field result from adjustments that seek to make the project as profitable as possible. Cash flows are projected and articulated. But the project should also be feasible, and the document takes care to demonstrate that acacias can grow in this area. The PDD indicates that Olivier has carried out small-scale field tests. It is also mentioned, as proof, that a large-scale acacia plantation financed by the European Union, as part of its development aid, is located not far from the project area. The agronomist from the consultancy firm considers that "the experience shows that it works well, so in principle it is not too risky to plant acacias" (Interview, March 15, 2010). The choice of acacia guarantees the biophysical possibility of a large-scale and longstanding plantation. The plantation design constitutes a safe and controlled option that is economically efficient and will secure a rapid return on investment. It represents the project in the near future, a project whose actualization seems thus to be technically, environmentally, and financially realistic.

Lowest risk, highest return, fast growing, secured cash flow: this is the vocabulary of financial investment. The project's material vehicle for providing a robust, foreseeable, and viable future is acacia, because to make the future state happen means making it economic (i.e. profitable). The rules used to assess the economic viability of the future are the rules of financial investment and thus of capitalization (see Tsing 2000; Leyshon and Thrift 2007; Nitzan and Bichler 2009; Muniesa 2012). Three important observations can be drawn from this. The first is that financial reasoning finds in the calculative space driven by the PDD a particularly hospitable site. Designing the plantation is a 
projective calculation on future viability. The discount methodologies provided by financial investment reasoning (the present value of an asset derives from its capacity to yield a return in the future) constitute a suitable frame for the determination of the value of the project. The second observation is that the figure of the investor is collapsed into the persona of the project developer. This reinforces the idea that, in a world in which political problems are addressed through economic projects, actors unfailingly adopt the identity of businesspersons, that is, entrepreneurs who integrate a capitalist reasoning. The third idea is that, construed as an object of investment, the projected forest becomes the material consequence of a discount methodology. The choice of species is heavily dependent on this reasoning, and the look of the future forest will most likely carry the mark of investment methodologies.

\section{Valuing the Project Against the Undesirable Counterfactual}

The PDD has to demonstrate that if the project is not implemented another state will occur. This other future state is called the baseline and requires a form of counterfactual projective proof. Counterfactual reasoning entails reflecting on possible worlds and imagining and manipulating events that are not actualized. It also involves the fulfilment of a credibility constraint: the imagined world needs to be different from the actual one, but at the same time similar to it. While the baseline needs to display strong likelihood, it also has to be less desirable than the world that the project would bring into existence. The project has value precisely because it foresees the construction of a world that is better than the one resulting from the imaginary manipulation translated into the baseline. The PDD not only has to create possible worlds, but also to demonstrate their veracityendorsing in practice a realist approach to counterfactuals (Lewis 1973; Stalnaker 1976; 1984, 147-169)—and to compare their respective environmental value.

Olivier likes to present the baseline as an obvious and evident matter of fact: if the project is not implemented, the land will repeatedly be degraded by fire. This is, in his words, "the reality" (Interview, March 17, 2010). But not everybody considers such kind of counterfactual benchmark an obvious matter. The idea of the baseline and the principle of additionality were hotly debated during the conception and fine-tuning of the CDM (Michaelowa 2005). It is still subjected to assessment in the economic academic literature (Schneider 2009; Grubb, Laing, Counsell, and Willan 2011), and critics of carbon markets often stress this point. Larry Lohmann, a researcher and activist, considers that "to disentangle a single baseline necessitates framing the political question of what would have happened without projects as matter of technical prediction in a deterministic system about which near-perfect knowledge is in 


\section{Valuation Studies}

principle possible" (Lohmann 2009, 511; see also Lohmann 2005). This, apart from being deeply difficult, means avoiding the political nature of collective decisions.

The fact that the project developer has to elaborate a baseline signifies that he is the only free decision-maker, while other actorsthe government, surrounding inhabitants, etc.-are framed as passive agents. Referring to Callon (1998), Lohmann states that such framing creates overflows which he describes as political. He illustrates this point with the case of a reforestation project in Brazil supported by the World Bank. The project's argumentation was as follows: without the plantation project, which was meant to produce charcoal, the company's pig iron energy needs would be supplied by coal, a source of energy that emits more carbon. With the help of an NGO, residents wrote to the CDM Executive Board to demand it reject the project, given the implausibility of the counterfactual scenario. Described as "absurd," insofar as the company had always sustained a plantation for its energy needs, the baseline was even considered a form of blackmail. For Lohmann, this request was a way for opponents to contest the denial of their agency implied by the nature of the counterfactual demonstration. It should be understood as a means for them to criticize the environmental damages produced by the company's activities and not as a demand to correct the baseline.

In a sense, Lohmann takes the counterfactual claim required by the CDM as a denotative, factual claim. He does so in order to expose its lack of verisimilitude. This mirrors in a sense the positive defence of the reality of the counterfactual advocated by Olivier. But the counterfactual claim is, quite literally, a fiction responding to a set of rules. The counterfactual exercise proceeds "as if" the project developer could master the environment and the PDD could be read as some sort of a demiurgic narrative. Yet, the fiction needs to respect a number of narrative constraints, and one of them is continuity with the existing world (Stalnaker 1984). The case analysed by Lohmann breaks that rule: it is absurd because it introduces a sudden and radical breach of reality (the sudden decision to use coal instead of charcoal, when the latter was the source of energy for years, is indeed absurd given that nothing has change that would warrant such a shift).

In order produce counterfactual realism, instructions have been established. The CDM rules oblige the project developer to determine the baseline and to demonstrate the project's additionality by following a standard methodology, a "combined tool to identify the baseline scenario and demonstrate the additionality" published by the Executive Board (UNFCCC 2007). This procedure is divided into sequential rhetoric operations. The first requirement is to "identify credible alternative land-use scenarios that would have occurred on the land within the proposed project boundary in the absence of the afforestation or reforestation project activity under the clean 
development mechanism (CDM)" (UNFCCC 2007, p. 2). The list of realistic and credible scenarios must include one that contemplates the continued pre-project use of the land and another one that contemplates the implementation of the project but not its registration within the CDM (i.e. the project without carbon credits).

The guideline provides some clues about what it means for a baseline to be credible (for example, the "switch to land-use typical for the region") and, perhaps more clear, what it means to not be credible (for instance, the construction of an airport in "a rural region with low density population and weak road infrastructure") (UNFCCC 2007, 2-3). Extreme scenarios such as political or technological breakthroughs are not acceptable. But the whole idea of plausibility remains rather vague, as a consultant contributing to Olivier's PDD indicated, "We must show a little imagination. But we are not going to invent something completely hare-brained. [...] We should try to stick to what actually seems plausible, considering the kind of activity that may take place in the area." (Interview, March 15, 2010, our translation)

A lector in fabula operates within the counterfactual narrative (Eco 1979). The PDD is written for a particular reader: the Executive Board. Another consultant explained that the Executive Board's previous registration decisions for reforestation projects are good sources for understanding what the Board considers to be "credible." Once a project is registered, its PDD is published on the CDM's website. Examining how accepted applications articulate credibility criteria enables reasoning by analogy and helps project developers anticipate the expectations of the final reader, the Executive Board.

Olivier's PDD identifies four counterfactual scenarios: pre-project continuation ("unmanaged grassland with wildfire-dominated ecological conditions and natural succession regrowth dynamics"), two alternative scenarios ("fire control without introducing agricultural activities" and "slow agricultural and cattle breeding development through conventional activities"), and the project scenario with no CDM support (Field document: PDD, December 1, 2010 , p. 38). These scenarios are considered to be realistic for the following reasons: "the sectorial and local economic situation (dominated by subsistence farming), national policy (the area is not part of forest policy priorities) and international interests (to date aid programmes have only ventured into meeting local fuelwood needs with pilot plantations)" (Field document: PDD, December 1, 2010, p. 38).

The next step for the construction of the baseline is to "identify realistic and credible barriers that prevent realization of the land-use scenarios identified" and to assess which of the scenarios is "not prevented by these barriers" (UNFCCC 2007, p. 4). This one will be the baseline. Among all possible credible scenarios, some of them 


\section{Valuation Studies}

would meet obstacles that could hamper their hypothetical actualization. The document provides examples of foreseeable barriers: investment barriers such as "lack access of credit" (UNFCCC 2007, p. 5 ) or technological barriers such as "lack of infrastructure for implementation of the technology." Making the potential obstacles explicit is an instrument for demonstrating the likelihood of the different scenarios being actualized.

The scenario for slow agricultural development, for example, is supposed to be prevented by investment barriers, such as "existing activities similar to this scenario show low returns on investment" in the Democratic Republic of Congo; institutional barriers, such as "public funding for agricultural development is low"; and technological barriers, such as "the prevailing practices in the region is subsistence farming." The PDD demonstrates that the fire control scenario is also prevented by similar obstacles. Finally, the hampering of the scenario for a project with no CDM support is based mainly on an investment barrier: "the financial support of [the investors] to the present project is conditioned on CDM eligibility in order to make the whole project viable" (Field document: PDD December 1, 2010, p. 38-41). Indeed, Olivier managed to secure investments after the World Bank signed the letter of intent and showed interest in the project and its emissions reduction potential.

In Olivier's case, the baseline is the "business-as-usual" scenario: that the land will continue to be degraded by periodic fires is the counterfactual against which the outcomes of the project will be compared. This baseline scenario can rightly be considered as quite matter-of-fact. In conversation, Olivier would insist that "you just need to visit the Congo and look at the land to come up with this." The rhetorical elaboration of the baseline is thus not a matter of reaching an intricate and sophisticated possible reality against which to value the reality of the project. It is rather a matter of constructing a narrative proof that forces to document and clarify a number of facts relative to the situation of the country and the foreseen activity. These facts are then inscribed into a stable and durable document, the PDD, which can be read and deemed robust by distant actors, such as the Executive Board of the CDM.

\section{Estimating the Credits: Virtual Metrology and Forward Sale}

Carbon credits generated by a reforestation project represent the difference between the "actual net greenhouse gas removals by sinks," that is, what is removed from the atmosphere as a result of the project, and the "baseline net greenhouse gas removals by sinks," that is, what would have been removed if the baseline was actualized (UNFCCC 2005). The production of this commodity and the calibration of its value require first a work of prospective estimation based on the difference between the project scenario and the baseline scenario. 
In the PDD, Olivier and the consultants have to accurately quantify something that does not yet exist. The quantification of the carbon hypothetically stored in the baseline condition is the easiest part. The $\mathrm{CDM}$ instructions indicate that in the case of reforestation, if the baseline is the pre-project land use, the baseline removals equal zero. The reasoning is based on the assumption that a degraded land will stay degraded. The ex-ante estimation of the carbon sequestered by the project scenario is more difficult. It requires the construction on paper of a virtual forest, a collection of trees with no biophysical connections reduced to quantities of different species- $\mathrm{x}$ acacias, $\mathrm{y}$ eucalyptusplanted at specified dates. ${ }^{3}$

To quantify the carbon stock, the PDD refers to default values and standard methods. Expected annual volume growth of trunks and expected volume of the aerial biomass (the branches)—obtained from the former through standard values of biomass expansion factor-are first determined. This expected total volume is then adjusted based on the standard density of the wood of the species and its standard carbon fraction. Through these operations, the virtual forest is translated into an anticipated amount of stored carbon. The project envisages the plantation of different varieties of acacia. Usually the carbon stored by a tree is highly dependent on the local conditions (soil, climate, slope, etc.). However, the PDD subsumes the different varieties into the generic designation "acacia" and default values are used. These values are provided by the guidebook of the Intergovernmental Panel on Climate Change (IPCC 2003), an intergovernmental body which provides expertise for climate negotiations (Edwards and Schneider 2001; Miller 2004). The IPCC's standards result from a massive work of data centralization, classification, and combination. The objective is to render the complexity of terrestrial carbon flows accessible to and actionable by policy-makers and non-experts.

The PDD's narrative simulates the growth of a virtual plantation of generic acacias and estimates the evolution of its carbon stock over the project's lifetime. This stock is expected to increase slowly at first and more rapidly after 2015. Such calculations determine the amount of carbon credits the project is expected to produce. They are required by the CDM instructions, but they are also necessary for a forward sale to be negotiated. As put by one of the consultants:

This is a work that is essential for the project developer in particular during the phase of the project's financial packaging, especially on a project like this one, where there are contracts to purchase carbon credits that were signed before the first field audit. This allows buyers to know what quantities they can expect after

${ }^{3}$ Carbon is also stored in the soil, the dead wood and litter but the modalities of the $\mathrm{CDM}$ enable project developers to exclude this other carbon pools from their monitoring. 


\section{Valuation Studies}

how many years. However, there is no guarantee that the reality will be exactly the same as the one initially estimated. It gives, let's say, a good approximation. But that's all. (Interview, March 15, 2010, our translation)

The World Bank, as a trustee of the BioCarbon Fund, participates in the calculation of the ex-ante quantification of carbon stocks. Since it committed itself in 2009 to buy half a million credits generated in 2017 , it needs to be sure that at least half a million tons of carbon are going to be stored by that date. Olivier sold part of the anticipated credits before the submission of the PDD to the World Bank. The latter purchased the credits on behalf of the investors of the fund, mostly governments committed to reducing their emissions. Olivier also sold some credits to a French investment bank, which agreed to buy the future commodities to resell them to clients seeking to voluntarily offset their emissions.

By signing transaction contracts called Emissions Reduction Purchase Agreement (ERPA), the buyers purchased primary credits, which are carbon credits bought directly from the project. As in Olivier's case, this often occurs before the CER credits are properly issued, meaning before the activity is fully implemented and verified. The emissions reductions become secondary credits when the first buyer resells them to a final user, which will use them to offset its own emissions. This second transaction often occurs once the credits appear on a registry and represent the actual physical removal of carbon from the atmosphere. As one of the representatives of the French investment bank put it, "these credits have been certified already, which means that they in fact exist!" (Interview, March 5, 2010). Olivier's primary credits exist only by virtue of the ex-ante estimations included in the PDD and mentioned in the ERPA. The contracts enact a forward sale and the price is supposed to reflect the risk of non-delivery. Its determination seemed to have been unilateral because, according to Olivier, the World Bank imposed its price, four dollars a ton. The price determined in the contract between Olivier and the French investment bank approached the same amount. Indeed, forestry is a rather marginal sector of the global carbon market. Few buyers participate in this market, which translates into such forms of asymmetry in pricing power. ${ }^{4}$

\footnotetext{
${ }^{4}$ Several things explain this. First the credits produced by reforestation projects are considered by the CDM to be temporary. They offset emissions just during a limited period. Thus, after a while, the buyer will need to replace them. Second, given their temporary nature and the controversies generated by the inclusion of reforestation activities in the CDM, these credits were excluded from the European cap-and-trade carbon market (see MacKenzie 2009a for a description of this other scheme). The European regulation authorizes the use of CERs from other kinds of activities and makes them fungible with quotas. As this market is the main demand for credits, the exclusion of the forestry CERs hampers the ability for project developers to find buyers.
} 
The signing of the ERPA between Olivier and the French investment bank depended on the "quality" of the project. The quality is to be understood as the project's capacity to demonstrate that the initiative is likely to be accepted by the Executive Board and that its implementation will be consistent with the ex-ante estimates, especially in terms of the amount of credits. To resell the credits, the bank has to make sure that they will actually be generated. The registration of the project within the CDM is the sine qua non condition of getting the primary emissions reductions purchased in advance and reselling them as secondary credits. It depends on the success of the project developer performing the different prospective operations and in particular demonstrating that the project could not have occurred without the access to the carbon market. But the quality of the project is also its ability to please the final user of the carbon credits. Additionality is in fact a marketing argument, along with "the story" that potential clients expect, as a representative of the French investment bank put it (Interview, January 18, 2010). This informant added that, for the bank, "a forestry project that aims at producing eucalyptus biomass in Brazil is rubbish," because it is not likely to interest clients who want to compensate their emissions. In contrast, Olivier's reforestation project is deemed valuable because of the touching narrative it is embedded in:

We really are in a country that is emerging from war, with people completely idle. And it is clear that any economic activity that we could promote is essential for the stability in the country. There are truly enormous social impacts and then, for that project, there are also tremendous environmental impacts, because the purpose of this project is to supply Kinshasa, which is one of the largest African capitals, with firewood, firewood that is normally exploited illegally in natural forests. Therefore one of the consequences of the project is a drop in pressure on natural forests and an involvement in the protection of the Congo basin and thus in the conservation of biodiversity. (Interview, January 18, 2010)

The "story" of the project is that it takes place in a difficult political context, an African post-war situation, and implies that buying carbon credits from the Belgo-Congolese project developer means changing this situation. As in the case of fair trade, such "producer story" is part of a "marketing of ethics" (Neyland and Simakova 2009). Olivier's project even appears on an advertising document that the marketing director of the French investment bank likes to circulate. Next to a photography that represents black people working the land, a short text describes the social, economic, and environmental benefits of the activity, stressing that the project will "boost the region's economic activity." The success of the project thus relies on the establishment of a storyline, a plot that elaborates the counterfactual display. It is circulated, publicised, and enacted in business fairs and events such as the Carbon Expo-an annual event 


\section{Valuation Studies}

organized by the World Bank and a consortium of enterprises in order to stimulate encounters within the carbon market. There, to anyone interested, Olivier told the story of the Congo war in the 1990s, his father's land, the customary chiefdom identifiable by the feather in his hat, the transformation into a carbon project, and the opportunity to supply Kinshasa with sustainable charcoal.

\section{Discussion: Calculative Contrivance, Counterfactual Reality, and Entrepreneurial Drive}

The case study we have presented illustrates the important role played by counterfactual display in the valuation of projects that rely on the establishment of a prospective reality. The notion of counterfactual display refers to the articulation of a difference between two possible and plausible realities: one controlled by the project under valuation, and one in which this project is absent. Counterfactual display is more than counterfactual reasoning. It is a form of demonstration that involves exhibiting technical documentation, following rhetorical moves orchestrated by rules, and framing prospective calculation. The description of the offsetting reforestation project is based on the construction of a virtual forest, and the project's value stems from its contrast with its virtual absence. But here, quite in line with the performative understanding of virtuality that can be found in process philosophy and pragmatism, "virtual" means "consequential" rather than "not real" (Muniesa, forthcoming).

The first insight that can be extracted from our research is on calculative contrivance. The scene set for the counterfactual display is contrived. It is the outcome of intense political preparation. However, as our research suggests, one crucial objective of this work is to create a space in which this preparation is no longer visible. The objective is to purify the expression of the counterfactual display and to provide a site of calculation that no longer requires tactical negotiations, strategic alliances, and critique of terms. In a sense, the counterfactual scene and its attached documentary apparatus fit the characteristics of a "centre of calculation," as theorized by Latour (1987): it allows novel realities to form (it calculates), but at the expenses of concealing the background displacements on which it stands. This is consequential insofar as the actual future reality resulting from calculation (a reality of trees, land, people, carbon, and money) ought to inherit from this condition of calculative contrivance.

The second insight is on counterfactual reality. What the counterfactual display does is to play a series of scenarios against each other, that is, of commensurable possible worlds which articulate actionable answers to a set of conditional queries (What will happen if the project does not take place? What will happen if the project takes place? What will happen if carbon credits are not allowed?). The differences between these scenarios translate directly into the valuation 
of the project, valuation in the sense of the estimation of its desirability and of the likelihood of its delivery. They also translate, quite prosaically, in the amount of carbon credits to be produced and hence, by extension, into the revenues of the project. Calling this compound of possible worlds a fiction should not be read as a disqualification of its reality. Agreeing that a possible world is indeed possible means siding, in a sense, with the realist approach to counterfactuals defended in philosophy by Stalnaker (1984, 147-169). Conditional counterfactual expressions can be claims for truth and assessed as such. Possible worlds are indeed virtual worlds that characterise the actual one. The rules of plausibility, contiguity, and, above all, auditability that govern counterfactual display in our case study meet with this viewpoint.

The third insight is on entrepreneurial drive. Our case study raised questions about the "how" of this counterfactual characterisation, and also the "by who" and "for whom." The counterfactual display emphasises the entrepreneurial nature of the projected reality. The anticipation of economic return and the aversion to business risks in the Democratic Republic of Congo act as essential criteria for both the viability of the activity and the determination of a scenario's reliability. Here, as is often the case with business parlance, a "credible project" means a project that can attract capital investment and generate profits in a reasonable time (i.e. rather quickly). This is why we suggest that the logic of capitalization determines to a great extent the template of the imagined possible worlds. This is why the entrepreneur, the buyer, and, to a lesser extent, the investor occupy central positions in the project's conditional plot. The Congolese administration is excluded from the prospective operations enacted within the PDD and from the market transaction, as are the people in the area surrounding the project site. These traditional political institutions-the state and its population-fade in favour of the CDM regulatory framework and its audit procedures. In contemporary capitalism, the "project" stands as an archetypical form of economic conduct, a standard for the expression of the connectedness and creativity of a liberal entrepreneur, as signalled by Boltanski and Chiapello (2005). Climate change negotiations have come to adopt this form as a critical instrument for the implementation of international climate policy and the promotion of collective action.

These insights are limited to the type of prospective valuation practices examined here and, perhaps more narrowly, to a single case. However, we conjecture that they would be helpful in understanding the problems of prospective valuation in general. Counterfactual display is something that can be more or less explicit, more or less articulate. Its explicitness and articulation are rather significant in carbon offsetting and, more generally, in climate change politics. But counterfactual display is at work, with its nuances and traits, in many 


\section{Valuation Studies}

other instances of economic valuation. The anthropology of financial valuation presented by Ortiz (2013), for example, interrogates the virtual scenarios that govern the practices of investment in the financial services industry, which implies drawing attention to the meanderings of counterfactual display in financial valuation formulas. Tracing the moral and political work that translates into the organization of a particular calculative setting, examining the criteria of truth and reality that inform the idea of future value, and scrutinizing the persona of the "free investor" that confers meaning to valuation, as Ortiz (2013) does, amounts to enriching the understanding of calculative contrivance, counterfactual reality, and entrepreneurial drive in valuation practices. Similarly, the comparative sociology of the monetary valuation of environmental damage proposed by Fourcade (2011) involves an inquiry into the articulation of possible worlds that is at stake in the analysis of contingent valuation. Putting emphasis on the different styles of statistical practice and their effects, engaging with the ways in which the "What if" question is made actionable, and observing the operations of a capitalist mode of thought are also part, in our view, of an elucidation of the three significant aspects of counterfactual display that we extracted from our case study.

\section{Conclusion}

Today, planting trees is one initiative in the collective struggle against climate change. But these carbon sinks, it is said, need to be economically viable. The system propelled by the Kyoto Protocol relies on the instauration of economic incentives that are meant to enable, at the lowest possible cost, favourable arrangements for the reduction of carbon emissions or for the removal of carbon from the atmosphere. Carbon offsetting reforestation projects are one example of such arrangements. As our case study illustrates, they rely on documentation. And it is within this documentation where the craft of counterfactual display resides: the demonstration of the value of the conditional world controlled by the project developer and made possible by the purchasers of the generated carbon credits and by the investors interested in the profitability of the activity.

There are several ways in which things could have been different. Reforestation initiatives could have been bound to sovereign determination and relied exclusively on the mechanisms of state policing and public finance, with the idea of carbon offsetting being dropped and a democratic state being placed at the centre of the climate arrangement. It is all a question of plausibility. But plausibility is a ductile condition, and the propagation of modes of valuation that orient reality in one direction makes other possible worlds less and less "credible." Today, for example, negotiations around REDD+ (Reducing Emissions from Deforestation and Forest Degradation in 
Developing Countries) are reopening the debate about how to organize collective action. While some negotiators defend a neater implication of governments, a more nuanced role for private entrepreneurship, and a more affirmative presence of civil society, the project polity is a persistent option, which gains solidity from the fact that offsetting forestry projects are already implemented..$^{5}$

We suggest that reflection on the transformation of the politics of global nature requires an examination of the devices of valuation that are mobilized. The notion of counterfactual display contributes, we believe, to that task. Defined as the practice of articulating and demonstrating prospective conditional scenarios, and considered from the vantage point of an anthropology of documentation, counterfactual display can be identified in a number of situations and, hence, be considered as a promising topic in the emerging repertoire of valuation studies.

Acknowledgements. The research on which this paper is based has benefited from funding from the European Research Council (ERC Starting Grant No. 263529), and from a visiting position at Columbia University (Department of Middle Eastern, South Asian and African Studies, February to April 2012). A previous version of this paper was presented at the $1^{\text {st }}$ Interdisciplinary Market Studies Workshop (Stockholm, 3-4 June 2010). We thank Luis Araujo, Brice Laurent, Morgan Meyer, Claes-Fredrik Helgesson, Karin Thoresson and two anonymous reviewers for comments and remarks on this work.

\section{References}

Armatte, Michel. 2008. "Climate Change: Scenarios and Integrated Modelling." Interdisciplinary Science Reviews 33 (1): 37-50.

Bäckstrand, Karin, and Eva Lövbrand. 2006. "Planting Trees to Mitigate Climate Change: Contested Discourses of Ecological Modernization, Green Governmentality and Civic Environmentalism." Global Environmental Politics 6 (1): 50-75.

Beckert, Jens. 2013a. "Imagined Futures: Fictional Expectations in the Economy." Theory and Society 42 (3): 219-240.

Beckert, Jens. 2013b. "Capitalism as a System of Expectations: Toward a Sociological Microfoundation of Political Economy." Politics and Society 41 (3): 323-350.

\footnotetext{
5 This observation is based on the first author's doctoral research, which includes an investigation on REDD+ negotiations.
} 


\section{Valuation Studies}

Boltanski, Luc, and Ève Chiapello. 2005. The New Spirit of Capitalism. London: Verso.

Boyd, Emily, Esteve Corbera, and Manuel Estrada. 2008. "UNFCCC Negotiations (Pre-Kyoto to COP-9): What the Process Says About the Politics of CDM-Sinks." International Environmental Agreements: Politics, Law and Economics 8 (2): 95-112.

Boyd, Emily. 2009. "Governing the Clean Development Mechanism: Global Rhetoric Versus Local Realities in Carbon Sequestration Projects." Environment and Planning A 41 (10): 2380-2395.

Callon, Michel. 1986. "Some Elements of a Sociology of Translation: Domestication of the Scallops and the Fishermen of St Brieuc Bay." In Power, Action and Belief: A New Sociology of Knowledge?, edited by John Law, 196-233. London: Routledge.

Callon, Michel. 1998. “An Essay on Framing an Overflowing: Economic Externalities Revisited by Sociology." In The Laws of the Markets, edited by Michel Callon, 244-269. Oxford: Blackwell.

Callon, Michel. 2009. "Civilizing Markets: Carbon Trading Between In Vitro and In Vivo Experiments." Accounting, Organizations and Society 34 (3-4): 535-548.

Callon, Michel, and Bruno Latour. 1981. "Unscrewing the Big Leviathan: How Actors Macrostructure Reality and How Sociologists Help Them to Do So." In Advances in Social Theory and Methodology: Toward an Integration of Micro- and Macro-Sociologies, edited by Karin KnorrCetina and Aaron V. Cicourel, 277-303. Boston: Routledge and Kegan Paul.

Callon, Michel, and Fabian Muniesa. 2005. "Economic Markets as Calculative Collective Devices." Organization Studies 26 (8): 1229-1250.

Corbera, Esteve, and Katrina Brown. 2008. "Building Institutions to Trade Ecosystem Services: Marketing Forest Carbon in Mexico." World Development 36 (10): 1956-1979.

Dahan, Amy, 2010. "Putting the Earth System in a Numerical Box? The Evolution from Climate Modeling Toward Global Change." Studies in History and Philosophy of Science Part B: Studies in History and Philosophy of Modern Physics 41 (3): 282-292.

Doganova, Liliana, and Marie Eyquem-Renault. 2009. "What Do Business Models Do? Innovation Devices in Technology Entrepreneurship." Research Policy 38 (10): 1559-1570.

Eco, Umberto. 1979. The Role of the Reader: Explorations in the Semiotics of Texts. Bloomington, IN: Indiana University Press.

Edwards, Paul N., Stephen H. Schneider. 2001. "Self-Governance and Peer Review in Science-for-Policy: The Case of the IPCC Second Assessment Report." In Changing the Atmosphere: Expert Knowledge and Environmental Governance, edited by Clark A. Miller and Paul N. Edwards, 219-246. Cambridge, MA: The MIT Press. 
Elyachar, Julia. 2005. Markets of Dispossession: NGOs, Economic Development, and the State in Cairo. Durham, NC: Duke University Press.

Edwards, Paul N. 2010. A Vast Machine: Computer Models, Climate Data, and the Politics of Global Warming. Cambridge, MA: The MIT Press.

Fogel, Cathleen. 2004. "The Local, the Global, and the Kyoto Protocol." In Earthly politics: Local and Global in Environmental Governance, edited by Sheila Jasanoff and Marybeth Long Martello, 103-125. Cambridge, MA: The MIT Press.

Foucault, Michel. 2008. The Birth of Biopolitics: Lectures at the Collège de France, 1978-1979. Basingstoke: Palgrave Macmillan.

Fourcade, Marion. 2011. "Cents and Sensibility: Economic Valuation and the Nature of 'Nature'." American Journal of Sociology 116 (6): 17211777.

Giraudeau, Martin. 2008. "The Drafts of Strategy: Opening up Plans and their Uses." Long Range Planning 41 (3): 291-308.

Grubb, Michael, Tim Laing, Thomas Counsell, Tand Catherine Willan. 2011. "Global Carbon Mechanisms: Lessons and Implications." Climatic Change 104(3-4): 539-573.

Guyer, Jane I. 2007. "Prophecy and the Near Future: Thoughts on Macroeconomic, Evangelical, and Punctuated Time." American Ethnologist 34 (3): 409-421.

Huault, Isabelle, and Hélène Rainelli-Weiss. 2011. "A Market for Weather Risk? Conflicting Metrics, Attempts at Compromise, and Limits to Commensuration." Organization Studies 32 (10): 1395-1419.

Intergovernmental Panel on Climate Change (IPCC). 2003. Good Practice Guidance for Land Use, Land Use Change and Forestry. Hayama: Institute for Global Environmental Strategies.

Jasanoff, Sheila, and Sang-Hyun Kim. 2009. "Containing the Atom: Sociotechnical Imaginaries and Nuclear Power in the United States and South Korea." Minerva 47 (2): 119-146.

Latour, Bruno. 1983. "Give Me a Laboratory and I Will Raise the World." In Science Observed: New Perspectives on the Social Studies of Science, edited by Karin D. Knorr-Cetina and Michael Mulkay, 141-170. London: Sage.

Latour, Bruno. 1987. Science in Action: How to Follow Scientists and Engineers through Society. Cambridge, MA: Harvard University Press.

Lave, Rebecca, Martin Doyle, and Morgan Robertson. 2010. "Privatizing Stream Restoration in the US." Social Studies of Science 40 (5): 677-703.

Lewis, David. 1973. Counterfactuals. Cambridge, MA: Harvard University Press.

Leyshon, Andrew, and Nigel Thrift. 2007. "The Capitalization of Almost Everything: The Future of Finance and Capitalism." Theory, Culture and Society 24 (7-8): 97-115. 


\section{Valuation Studies}

Li, Tania Murray. 2007. The Will to Improve: Governmentality, Development, and the Practice of Politics. Durham, NC: Duke University Press.

Lohmann, Larry. 2005. "Marketing and Making Carbon Dumps: Commodification, Calculation and Counterfactuals in Climate Change Mitigation." Science as Culture 14 (3), 203-235.

Lohmann, Larry. 2009. "Toward a Different Debate in Environmental Accounting: The Cases of Carbon and Cost-Benefit." Accounting, Organizations and Society 34 (3-4): 499-534.

Lövbrand, Eva. 2009. "Revisiting the Politics of Expertise in Light of the Kyoto Negotiations on Land Use Change and Forestry." Forest Policy and Economics 11 (5): 404-412.

Lövbrand, Eva, and Johannes Stripple. 2012. "Disrupting the Public-Private Distinction: Excavating the Government of Carbon Markets PostCopenhagen." Environment and Planning C: Government and Policy, 30 (4): 658-674.

Lovell, Heather, and Diana Liverman. 2010. "Understanding Carbon Offset Technologies.” New Political Economy 15 (2): 255-273.

MacKenzie, Donald. 2009a. Material Markets: How Economic Agents are Constructed. Oxford: Oxford University Press.

MacKenzie, Donald. 2009b. "Making Things the Same: Gases, Emission Rights and the Politics of Carbon Markets." Accounting, Organizations and Society 34 (3-4): 440-455.

Mallard, Grégoire, and Andrew Lakoff. 2011. "How Claims to Know the Future Are Used to Understand the Present." In Social Knowledge in the Making, edited by Charles Camic, Neil Gross and Michèle Lamont, 339377. Chicago, IL: University of Chicago Press.

Maurer, Bill. 2002. "Repressed Futures: Financial Derivatives' Theological Unconscious." Economy and Society 31 (1): 15-36.

Michaelowa, Axel. 2005. "Determination of Baselines and Additionality for the CDM: A Crucial Element of Credibility of the Climate Regime." In Climate Change and Carbon Markets: A Handbook of Emissions Reduction Mechanisms, edited by Farhana Yamin, 289-304. London: Earthscan.

Miller, Clark A. 2004. "Climate Science and the Making of a Global Political Order." In States of Knowledge: The Co-Production of Science and Social Order, edited by Sheila Jasanoff, 46-66. Abingdon, Routledge.

Mitchell, Timothy. 2007. "The Properties of Markets." In Do Economists Make Markets? On The Performativity of Economics, edited by Donald MacKenzie, Fabian Muniesa and Lucia Siu, 244-275. Princeton, NJ: Princeton University Press.

Miyazaki, Hirokazu. 2006. "Economy of Dreams: Hope in Global Capitalism and Its Critiques." Cultural Anthropology 21 (2):147-172.

Muniesa, Fabian. 2012. "A Flank Movement in the Understanding of Valuation." In Measure and Value, edited by Lisa Adkins and Celia Lury, 24-38. Oxford: Wiley-Blackwell. 
Muniesa, Fabian. Forthcoming. The Provoked Economy: Economic Reality and the Performative Turn. Abingdon: Routledge.

Neyland, Daniel, and Elena Simakova. 2009. "How far can we push sceptical reflexivity? An analysis of marketing ethics and the certification of poverty." Journal of Marketing Management 25 (7-8): 777-794.

Nitzan, Jonathan, and Shimshon Bichler. 2009. Capital as Power: A Study of Order and Creorder. Abingdon, Routledge.

Ortiz, Horacio. 2013. "Financial Value: Economic, Moral, Political, Global." HAU: Journal of Ethnographic Theory 3 (1): 64-79.

Power, Michael. 1997. The Audit Society: Rituals of Verification. Oxford, Oxford University Press.

Schneider, Lambert. 2009. "Assessing the Additionality of CDM Projects: Practical Experiences and Lessons Learned." Climate Policy 9 (3): 242254.

Stalnaker, Robert C. 1976. "Possible Worlds." Nô̂s 10 (1): 65-75.

Stalnaker, Robert C. 1984. Inquiry. Cambridge, MA: The MIT Press.

Tsing, Anna. 2000. "Inside the Economy of Appearances." Public Culture 12 (1): 115-144.

United Nations Framework Convention on Climate Change (UNFCCC). 1997. "Decision 1/CP.3." In Kyoto Protocol to the United Nations Framework Convention on Climate Change, Annex, 7-30 (FCCC/CP/ 1997/7/Add.1). Bonn: UNFCCC.

United Nations Framework Convention on Climate Change (UNFCCC). 2001. "Decision 17/CP.7." In Report of the Conference of the Parties on its Seventh Session, Held at Marrakech from October 29 to November 10, 2001, Addendum, Part Two: Action Taken by the Conference of the Parties, Volume 2, 20-79 (FCCC/CP/2001/13/Add.2). Bonn: UNFCCC.

United Nations Framework Convention on Climate Change (UNFCCC). 2005. "Decision 5/CMP.1." In Report of the Conference of the Parties Serving as the Meeting of the Parties to the Kyoto Protocol on its First Session, Held at Montreal from November 28 to December 10, 2005, Addendum, Part Two: Action Taken by the Conference of the Parties Serving as the Meeting of the Parties to the Kyoto Protocol, 61-80 (FCCC/KP/CMP/2005/8/Add.1). Bonn: UNFCCC.

United Nations Framework Convention on Climate Change (UNFCCC). 2007. "A/R Methodological Tool: Combined Tool to Identify the Baseline Scenario and Demonstrate Additionality in A/R CDM Project Activity." In Executive Board of The Clean Development Mechanism Thirty-Fifth Meeting Report, Annex 19, 1-13. Bonn: UNFCCC. 


\section{Valuation Studies}

Véra Ehrenstein is currently concluding her doctoral research on international adjustments, tropical forests and carbon arrangements at the Centre de Sociologie de l'Innovation, in the Ecole des Mines de Paris (Mines ParisTech). Her research interests include science and technology studies, economic sociology and the anthropology of development.

Fabian Muniesa works as a senior researcher at the Centre de Sociologie de l'Innovation, in the Ecole des Mines de Paris (Mines ParisTech), and is the holder of an ERC Starting Grant (his project's title is "Performativity in Business Education, Management Consulting and Entrepreneurial Finance"). $\mathrm{He}$ is currently interested in the anthropology of capitalization. 